\title{
Radiological assessment of closure time of around elbow secondary ossification centers, in khartoum hospital, khartoum north hospital, omdurman hospital, police hospital, and umbadda hospital, in khartoum, Sudan(december 2009-2010)
}

\begin{abstract}
Background: Elbow joint is characterized by 6 secondary ossification centers; in the capitulum, trochlea, lateral and medial epichondyles, olecranon and head of the radius. They are present on plane elbow radiograph at different time easily remembered by the mnemonic CRITOE: Capitulum 2years; Radial head 4 years; Internal (medial) Epicondyle 6 years; Trochlea 8 years; Olecranon 10 years; external (lateral) Epicondyle 12 years. A prospective cross sectional hospital based study is conducted in period from December 2009 to December 2010 in which data was collected from 5 hospitals which provide services for the majority of the Khartoum state residents. The study aim to assess the time of closure of secondary ossification centers in Sudanese children.
\end{abstract}

Patient \& Methods: A prospective cross sectional hospital based study is conducted in period from December 2009 to December 2010 in which data was collected from 5 hospitals; Khartoum, Khartoum North, Omdurman, Police, and Um Badda. These hospitals provide services for the majority of the Khartoum state residents. Fifty seven AP and Lateral plane elbow X- ray were taken for healthy Sudanese children (40 Males and 17 Females) aged 13-23 years, whom sought medical counseling for skeletal problems at those hospitals.

Results: In this study, the films of the $1^{\text {st }}$ group (at average of 14 year) no one has closed RH, while only $20 \%$ of them show closed OC, ME, and LE, and $40 \%$ show closed T \& C. In the $2^{\text {nd }}$ group (at average of 17 year), $60 \%$ have closed RH physis, $63.3 \% \mathrm{Tr}$, while $66.7 \%$ show closed OC, $73.3 \%$ ME, and $90 \%$ for LE, and Cap. All children above $19 \mathrm{Ys}$ ( $3^{\text {rd }}$ group) have closed physis (Table 1). The female physeal fusion precedes the male one in all the 6 centers.

Conclusion: The study showed that all the 6 centers fuse to the shaft between 15 \& 19 Ys, that all were ossified above 19 Ys, but are still open at \& below 14 Ys. Female's fusion precedes males in all 6 centers. Order of fusion starts at trochlea, then capitulum followed by lateral Epicondyle, medial epicondyle, olecranon, and finally radial head.

Keywords: Epichondyles, Semi lunar Notch, Capitulum, Olecranon, Suprachondylar Fractures
Volume 8 Issue 3 - 2017

\author{
Sakher Alssayed Mohamed Ahmed \\ Alwahbany,' Tahir Osman Ahmed, ${ }^{2}$ Areeg \\ Dawoud Hussien ${ }^{3}$ \\ 'Orthopedic Surgeon \& Anatomist, Alzaeim Alazhary University, \\ Sudan \\ ${ }^{2}$ National ribate university, Sudan \\ ${ }^{3}$ Medical officer, $\mathrm{MOH}$, Sudan
}

\begin{abstract}
Correspondence: Sakher Alssayed Mohamed Ahmed Alwahbany, Orthopedic surgeon \& anatomist, Alzaeim Alazhary University, Sudan, Tel 250000000000 ,

Email sakherwahabany123@gmail.com
\end{abstract}

Received: May 08, 2017 | Published: May 31, 2017

\section{Introduction}

The elbow-joint is a synovial joint of hinge variety between distal humerus and proximal end of radius and ulna. ${ }^{1}$ In it the trochlea of the humerus is received into the semilunar notch of the ulna, and the capitulum of the humerus articulates with the fovea on the head of the radius. ${ }^{2}$

Elbow joint is characterized by 6 secondary ossification centers; in the capitulum, trochlea, lateral and medial epichondyles, olecranon and head of the radius. They are present on plane elbow radiograph at different time easily remembered by the mnemonic CRITOE: Capitulum 2years; Radial head 4 years; Internal (medial) Epicondyle 6 years; Trochlea 8 years; Olecranon 10 years; external (lateral) Epicondyle 12 years. ${ }^{3}$ The Capitulum, Trochlea \& Lateral epicondyle fuse in a single epiphysis with epiphyseal plate separating each from the shaft. The epiphyseal plate represents the site of bone lengthening. ${ }^{2}$ The secondary ossification centers play an important role in bone age $\&$ assessment of skeletal maturation as explained by the Sauvé Grain et al. ${ }^{4}$ method of assessing skeletal age from elbow radiographs, it is useful during the $2^{\text {nd }}$ years of the pubertal growth spurt; between 11 and 13 years in girls and between 13 and 15 years in boys. ${ }^{4}$ Distal humerus is a common site of fracture in children (suprachondylar fracture) that may represent $65.4 \%$ of total forearm fracture, ${ }^{5}$ with subsequent difficulty of differentiation between fracture line and physis as the radiographs may be misleading because: ${ }^{5}$

\section{The fragment consists mainly of cartilage.}

II. In children the fragment seems smaller than it actually is.

III. The displacement, although it is pronounced, may not seem appreciable.

Hence comparison with the normal side \& the knowledge of time of closure of epiphyseal plate is essential \& will enable differentiation between suprachondylar fractures; Salter-Harris fracture \& normal $\mathrm{x}$-ray, ${ }^{5}$ as fracture of the epiphyseal plate represent an orthopedic emergency. Physeal injuries, account for $30 \%$ of the fractures and 
occur twice as often in the upper extremities as compared to the lower extremities. Girls with physeal fractures are 1.5 years younger than boys with the same type of fracture in the same location..$^{5}$ Injuries that involve the physis and the epiphysis, historically, have caused cessation of growth and resultant angular deformities. ${ }^{5}$ The higher the classification, the more likely is physeal arrest or joint incongruity to occur. Minor injury can cause scarring, tethering, and arrest of the periphery of the physis, which may be the most crucial area regarding angular deformity.,

So the knowledge of the time of the closure of the secondary ossification centers around elbow joint helps in assessment of the bone age \& detecting any discrepancies from child chronological age. ${ }^{5,6}$ It also helps in radiological differentiation between normal elbow X.ray, suprachondylar fractures \& Salter Harris fracture \& consequently the patient may avoid the complications that follow missing of the injury. ${ }^{5,6}$ Pinning is the best choice for operative fixation of suprachondylar fracture in children with open epiphyseal plate as they are less injurious. ${ }^{5}$ The literature lacks figures for the ossification time around the elbow joint in Sudanese child even for African ones.

\section{Objectives}

To assess the time of closure of secondary ossification centers in Sudanese children, \& its correlation to international references.

\section{Materials and methods}

A prospective cross sectional hospital based study is conducted in period from December 2009 to December 2010 in which data was collected from 5 hospitals; Khartoum, Khartoum North, Omdurman, Police, and Um Badda. These hospitals provide services for the majority of the Khartoum state residents. Fifty seven AP and Lateral plane elbow X- ray were taken for healthy Sudanese children (40 Males and 17 Females) aged $13-23$ years, whom sought medical counseling for skeletal problems at those hospitals. A special form (questionnaire) was designed to collect personal data, and to assess the state of the bones and epiphyseal plates on radiographs. Any radiograph`s data not corresponding to inclusion criteria was excluded from the study.

\section{Inclusion criteria}

a. Apparently normal healthy subjects aged $13-23$ years.

b. Children who have a definite date of birth.

\section{Exclusion criteria}

i. Any chronic illness (e.g. congenital heart disease)

ii. Short stature.

iii. Severe malnutrition -weight age $<60 \%$

iv. Endocrinal disorders.

v. Chronic drug intake (e.g. anti-epileptic drugs, steroids)

\section{Radiological specification}

$\mathrm{X}$ ray left and right elbow -AP and lateral view

A. KV- 50 (centering at elbow joint)

B. mAs- 16

C. Tube distance- 36 inches

D. Tube of $200 \mathrm{~mA}$

E. Films used; $25 \mathrm{~cm}$ x $20 \mathrm{~cm}$ or $20 \mathrm{~cm}$ x $15 \mathrm{~cm}$.

$\mathrm{X}$ - Rays were put into three groups according to the age of the patients a. Those less than 15 years,

b. Those more than 19 years,

c. Those between 15 - 19 years

Any X-ray showing evidence of bony abnormality or disease, and all films whose ages and sexes were doubtful were discarding. Only normal X-rays for those within the target age group were included.

\section{Results}

\section{Samples}

In this study, $57 \mathrm{AP}$ and Lateral plane elbow X - Rays (including 40 males and 17 females) were assessed for the appearance of the physis of the six ossification centers around elbow joint for children aged 13- 23 years. $X$ - Rays films were put into three age groups; the $1^{\text {st }}$ is for those $<15$ year, the $2^{\text {nd }}$ is for those between $15-19$ year, and the $3^{\text {rd }}$ is for those $>19$ year. No differences were found between the right and the left sides so data of only one side was considered in analyzing the results.

\section{General results}

In this study, the films of the $1^{\text {st }}$ group (at average of 14 year) no one has closed RH, while only $20 \%$ of them show closed OC, ME, and LE, and $40 \%$ show closed T \& C. In the $2^{\text {nd }}$ group (at average of 17 year), $60 \%$ have closed RH physis, $63.3 \%$ Tr, while $66.7 \%$ show closed OC, $73.3 \% \mathrm{ME}$, and $90 \%$ for LE, and Cap . All children above 19 Ys ( $3^{\text {rd }}$ group) have closed physis (Table 1$)$.

\section{Males results}

In the $1^{\text {st }}$ group which is formed of 3 members $(7.5 \%)$ no one $(0 \%)$ is found to have closed $\mathrm{RH}$, and only one $(33.3 \%)$ found to have closed; OC, T, C, LE, and ME. The $2^{\text {nd }}$ group (19 members, $47.5 \%$ ) $7 \mathrm{RH}(36.8 \%)$ physes were found closed, $9 \mathrm{OC}(47.4 \%), 11 \mathrm{ME}$ (57.9\%), 16 Cap (84.2\%), 16 LE (84.2\%), and $18 \operatorname{Tr}(94.7 \%)$ physes were closed. In the $3^{\text {rd }}$ group (18 member, $45 \%$ ) the 6 centers were found closed in all members $(100 \%)$. No closed physes were found below 14 year in male radiographs (Tables 2-7) \& (Figures 1, 3, 5, 7, 9, and 11).

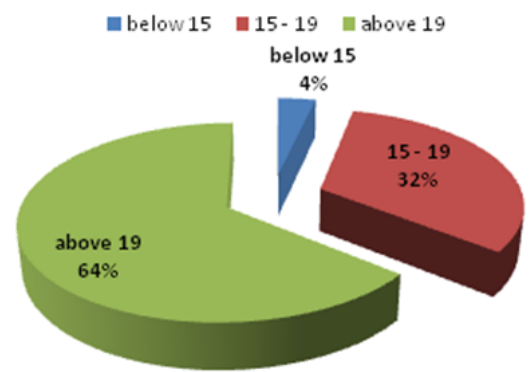

Figure I Frequency of OC closure in males.

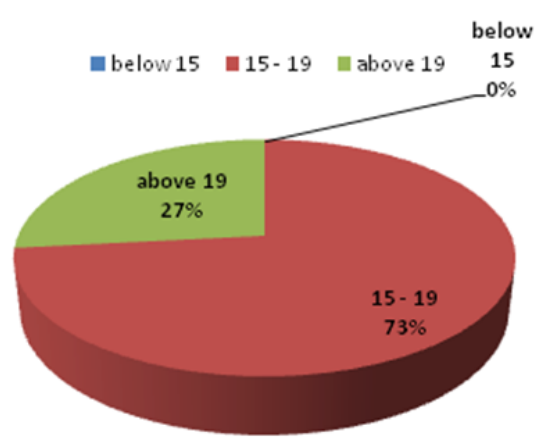

Figure 2 Frequency of $\mathrm{OC}$ closure in females. 
abelow15 घ15-19 घabove 19

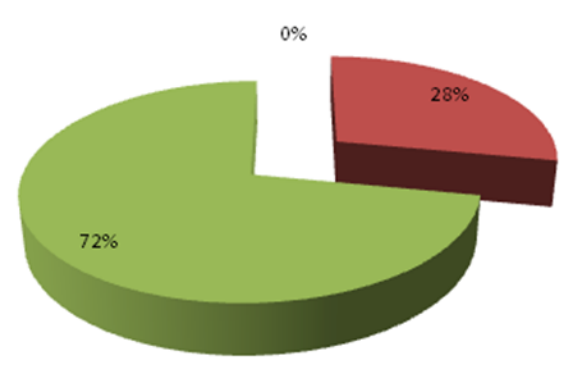

Figure 3 Frequency of $\mathrm{RH}$ closure in males.

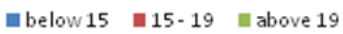

$0 \%$

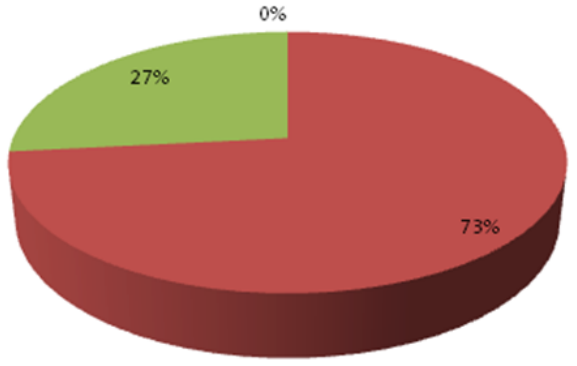

Figure 4 Frequency of RH closure in females.

abelow $15 \quad 15-19$ ॥above 19
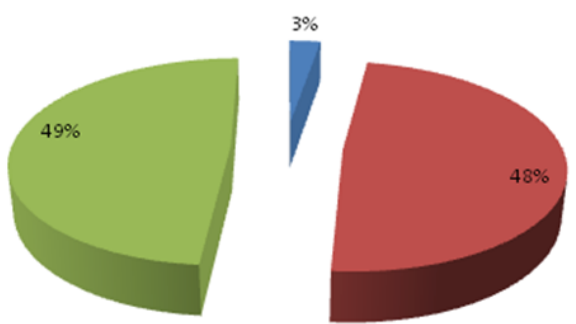

Figure 5 Frequency of $\operatorname{Tr}$ closure in males.

घbelow $15 \quad$ |15-19 || above 19

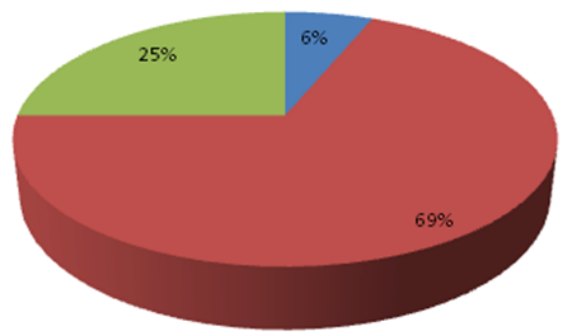

Figure 6 Frequency of $\operatorname{Tr}$ closure in females.

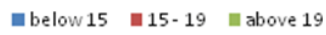
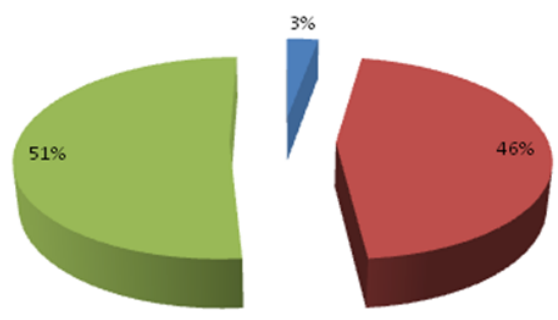

Figure 7 Frequency of $C$ closure in males. abelow 15 15-19 Inabove 19

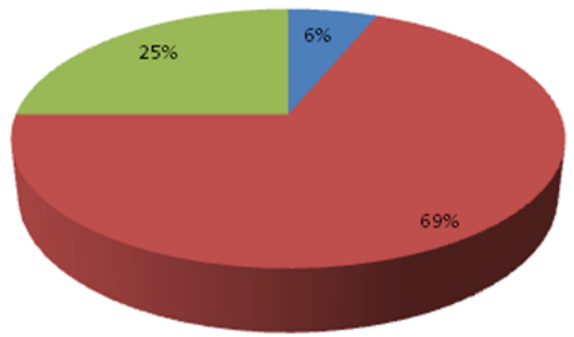

Figure 8 Frequency of $C$ closure in females.

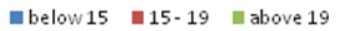

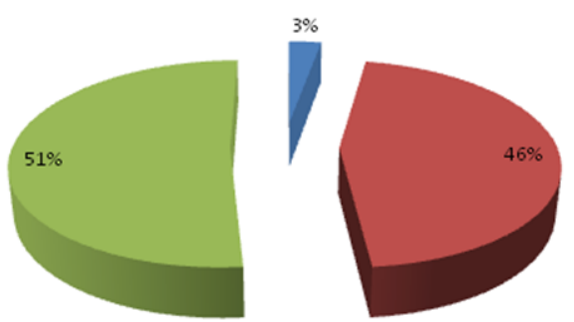

Figure 9 Frequency of LE closure in males.

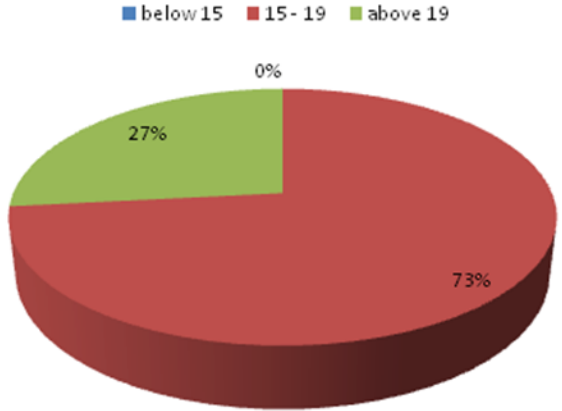

Figure I0 Frequency of LE closure in females.

घbelow $15 \quad$ घ15-19 $\|$ above 19

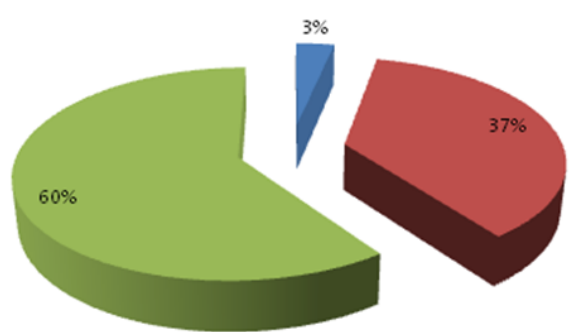

Figure I I Frequency of ME closure in males.

nbelow15 घ15-19 $\|$ above 19

$0 \%$

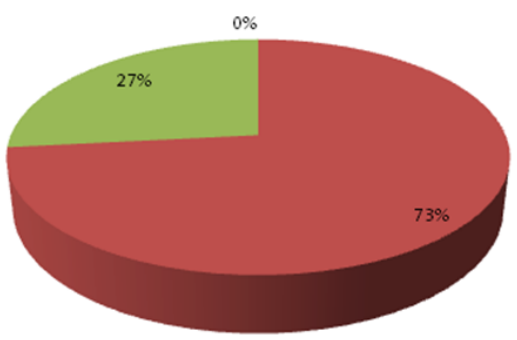

Figure 12 Frequency of ME closure in females.

Citation: Alwahbany SAMA, Ahmed TO, Hussien AD. Radiological assessment of closure time of around elbow secondary ossification centers, in khartoum hospital, khartoum north hospital, omdurman hospital, police hospital, and umbadda hospital, in khartoum, Sudan(december 2009-20I0). MOJ Orthop Rheumatol. 20I7;8(3): I I-I2. DOI: I0.I5406/mojor.20I7.08.003 I3 
Table I Frequency of closed center among different age groups

\begin{tabular}{|c|c|c|c|c|c|c|c|c|c|c|c|c|c|}
\hline \multirow{2}{*}{ Age Group (Ys) } & \multirow{2}{*}{$\begin{array}{l}\text { Total No of } \\
\text { Cases }\end{array}$} & \multicolumn{2}{|l|}{ OC } & \multicolumn{2}{|l|}{$\mathbf{R H}$} & \multicolumn{2}{|l|}{$\operatorname{Tr}$} & \multicolumn{2}{|l|}{ C } & \multicolumn{2}{|l|}{ ME } & \multicolumn{2}{|l|}{ LE } \\
\hline & & App & $\%$ & App & $\%$ & App & $\%$ & App & $\%$ & App & $\%$ & App & $\%$ \\
\hline$<15$ & 5 & I & 20 & 0 & 0 & 2 & 40 & 2 & 40 & I & 20 & I & 20 \\
\hline $15-19$ & 30 & 20 & 67 & 18 & 60 & 19 & 63.3 & 27 & 90 & 22 & 73.3 & 27 & 90 \\
\hline$>19$ & 22 & 22 & 100 & 22 & 100 & 22 & 100 & 22 & 100 & 22 & 100 & 22 & 100 \\
\hline Total & 57 & & & & & & & & & & & & \\
\hline
\end{tabular}

Table 2 Frequency of OC closure

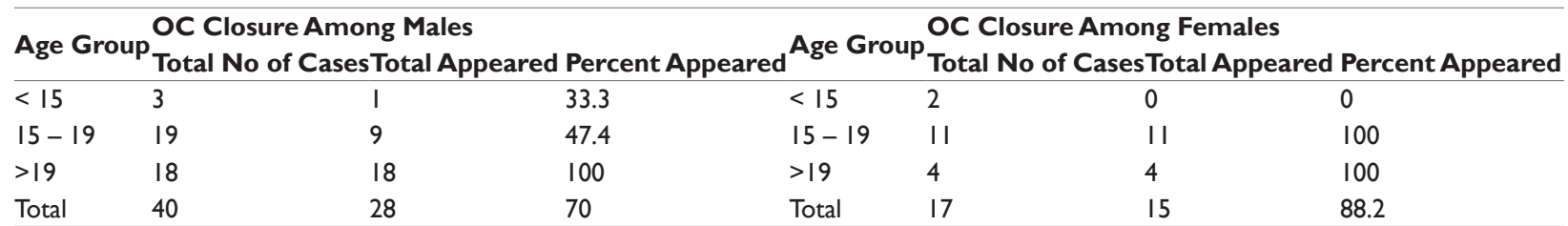

Table 3 Frequency of closure of $\mathrm{RH}$

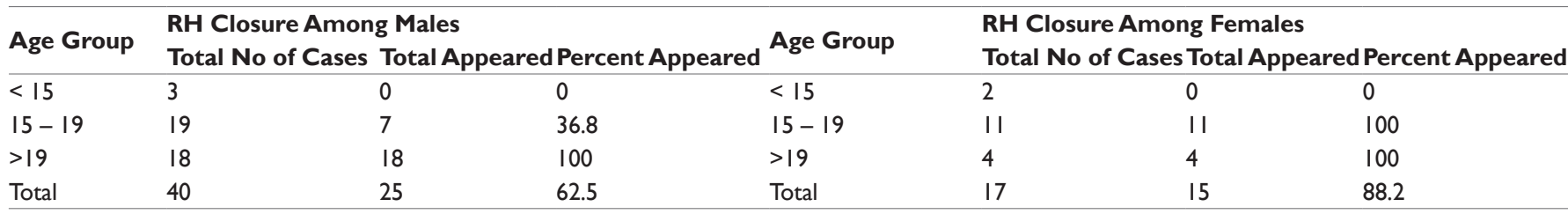

Table 4 Frequency of closure of $\mathrm{Tr}$

\begin{tabular}{llllllll}
\hline \multirow{2}{*}{ Age Group } & \multicolumn{2}{l}{ Tr Closure Among Males } & \multicolumn{3}{l}{$\begin{array}{l}\text { Tr Closure Among Females } \\
\text { Total No of Cases Total Appeared Percent Appeared }\end{array}$} & $\begin{array}{l}\text { Age Group } \\
\text { Total No of Cases }\end{array}$ & \multicolumn{2}{c}{ Total Appeared Percent Appeared } \\
\hline$<15$ & 3 & 1 & 33.3 & $<15$ & 2 & 1 & 50 \\
$15-19$ & 19 & 18 & 94.7 & $15-19$ & 11 & 11 & 100 \\
$>19$ & 18 & 18 & 100 & $>19$ & 4 & 4 & 100 \\
Total & 40 & 37 & 92.5 & Total & 17 & 16 & 94.1 \\
\hline
\end{tabular}

Table 5 Frequency of closure of $C$

\begin{tabular}{|c|c|c|c|c|c|c|c|}
\hline Age Group & \multicolumn{3}{|c|}{ Cap Closure Among Males } & Age Group & \multicolumn{3}{|c|}{ Cap Closure Among Females } \\
\hline$<15$ & 3 & I & 33.3 & $<15$ & 2 & I & 50 \\
\hline $15-19$ & 19 & 16 & 84.2 & $15-19$ & 11 & II & 100 \\
\hline$>19$ & 18 & 18 & 100 & $>19$ & 4 & 4 & 100 \\
\hline Total & 40 & 35 & 87.5 & Total & 17 & 16 & 94.1 \\
\hline
\end{tabular}

Table 6 Frequency of closure of LE

\begin{tabular}{|c|c|c|c|c|c|c|c|}
\hline \multirow{2}{*}{ Age Group } & \multicolumn{3}{|c|}{ LE Closure Among Males } & \multirow{2}{*}{ Age Group } & \multicolumn{3}{|c|}{ LE Closure Among Females } \\
\hline & Total No of Cases & Total Appeared & Percent Appeared & & Total No of Cases & Total Appeared & Percent Appeared \\
\hline$<15$ & 3 & I & 33.3 & $<15$ & 2 & 0 & 0 \\
\hline $15-19$ & 19 & 16 & 84.2 & $15-19$ & II & II & 100 \\
\hline$>19$ & 18 & 18 & 100 & $>19$ & 4 & 4 & 100 \\
\hline Total & 40 & 35 & 87.5 & Total & 17 & 15 & 88.2 \\
\hline
\end{tabular}

Table 7 Frequency of closure of ME

\begin{tabular}{|c|c|c|c|c|c|c|c|}
\hline \multirow{2}{*}{ Age Group } & \multicolumn{3}{|c|}{ ME Closure Among Males } & \multirow{2}{*}{ Age Group } & \multicolumn{3}{|c|}{ ME Closure Among Females } \\
\hline & Total No of Cases & Total Appeared & Percent Appeared & & Total No of Cases & Total Appeared & Percent Appeared \\
\hline$<15$ & 3 & 1 & 33.3 & $<15$ & 2 & 0 & 0 \\
\hline $15-19$ & 19 & 11 & 57.9 & $15-19$ & 11 & 11 & 100 \\
\hline$>19$ & 18 & 18 & 100 & $>19$ & 4 & 4 & 100 \\
\hline Total & 40 & 30 & 75 & Total & 17 & 15 & 88.2 \\
\hline
\end{tabular}

Table 8 Comparison of closure of center between both sexes

\begin{tabular}{lllllll}
\hline Sex & $\mathbf{O}$ & RH & Tr & C & ME & LE \\
\hline Male (40) & $70 \%$ & $62 \%$ & $92.50 \%$ & $87.50 \%$ & $87.50 \%$ & $75 \%$ \\
Female (17) & $88.20 \%$ & $88.20 \%$ & $94.10 \%$ & $94.10 \%$ & $88.20 \%$ & $88.20 \%$ \\
\hline
\end{tabular}




\section{Females results}

In the $1^{\text {st }}$ group of 2 members no one has closed; OC, RH, LE, and ME, while $50 \%$ were found to have closed $\mathrm{Tr}$ and $\mathrm{C}$. All members of the $2^{\text {nd }}$ group (11members; $74.7 \%$ ) and $3^{\text {rd }}$ group ( 4 members; $23.5 \%$ ) showed closed centers. From the total number of females $88.2 \%$ were found to have closed; OC, RH, LE, and ME, while $94.1 \%$ had closed Tr and Cap (Tables 2-7) \& (Figures 2, 4, 6, 8, 10, and 12).

\section{Discussion}

Elbow joint is a hinge synovial joint that enables the person to perform an essential task which is considered very important for the person to accomplish his (her) daily normal live activities. To perform that, the elbow joint must be at a normal position and orientation. Distal humerus represents a common site of fractures in children with suprachodylar fracture frequency of $65.4 \%$ of total forearm fractures, ${ }^{5}$ and physeal injuries accounting for $30 \%$ of the fractures. The fractures occur twice as often in the upper extremities compared to the lower extremities. All these factors increase the chance of dysfunction of elbow joint in the form of angular deformity. It is difficult to differentiate between fracture \& physis, as the radiographs may be misleading because; ${ }^{5}$ the fragment consists mainly of radiolucent cartilage so it seems smaller than it actually is, and the displacement although it is pronounced may not seem appreciable. Injury to physis either via direct trauma or during orthopedic surgery causes either cessation of growth or angular deformity.

So proper reading and diagnosis of elbow joint $\mathrm{X}$-rays by comparison with the normal side \& good knowledge of time of closure of epiphyseal plate; which is lacking for local children even for African one, is essential \& enable differentiation between supracondylar fractures; Salter-Harris fractures \& normal X-ray, ${ }^{5}$ and subsequently preserving the function of the elbow if possible. Pinning is the best choice for operative fixation of supracondylar fractures in children with open epiphyseal plate, as they are less injurious ${ }^{5}$ to the physis; raise a second need for proper reading of the elbow radiograph.

In this study the trochlea center is the first to ossify that $40 \%$ of the radiographs show closed physes below 15 Ys, while $96.7 \%$ of them were closed between $15 \& 19$ Ys, and no open physis can seen above 19Ys. The $2^{\text {nd }}$ in frequency is the capitulum that, below 15 Year, $40 \%$ of the physes were closed, and $90 \%$ were closed between $15 \& 19$ Year, while all above 19 Year were found to be closed. The $3^{\text {rd }}$ center to be closed is the lateral epicondyle with frequency of 20 $\%$ below 15 Year, 83.3\% between $15 \& 19$ Year, and $100 \%$ above 19 Year. Medial epicondyle come the $4^{\text {th }}$ in frequency that only $20 \%$ were closed below 15 Year, while $73.3 \%$ between the $15-19$ Year, and all those above the 19 Year had closed physis. The $5^{\text {th }}$ is the olecranon with $20 \%$ were closed below 15 Year, $66.7 \%$ between 15 \& 19 Year, but no open olecranon physis expected to be seen above 19 Year (100 $\%$ fusion). The last in frequency (6th) is the radial head physis, that below 15 Year the physis can be seen but soon fuse to the shaft that between $15-19$ Year $60 \%$ of these were fused, \& no one can be seen above 19 Year.

The female physeal fusion precedes the male one in all the 6 centers (Table 7). In comparison of study result to internationally published figure it was found that all the four physes around elbow joint fused to their corresponding shaft between 15-19 year of age with average of 17.5 year compared to 16 year of age for all physes around elbow in; Indian children as showed by Marak et al. ${ }^{7}$ Bengal children as explained by Banerjea AK \& Rao MN. ${ }^{8}$ No local, regional, or African published paper is available to compare it to study result.

\section{Conclusion}

i. The study showed that all the 6 centers fuse to the shaft between $15 \& 19$ Ys, that all were ossified above 19Ys, but are still open at \& below 14 Ys.

ii. Female's fusion precedes males in all 6 centers.

iii. Order of fusion starts at trochlea, then capitulum followed by lateral epicondyle, medial epicondyle, olecranon, and finally radial head.

\section{Recommendations}

A. Any trauma to the elbow joint between 15-19 Ys must be taken serious, as the physis is open and physeal injury must be excluded clinically and radiologically.

B. Any surgical intervention in children between 15-19Ys must be taking in consideration the open physis.

C. Above 19 years of age all the 6 physes are closed, so the risk of physeal injury following trauma is minimal and no physeal precaution is needed during surgery.

D. Any radiograph showing open physis above 19 year or closed one below 15 year of age must be taken seriously as it is abnormal.

E. A system of archiving data must be established in hospitals and medical centers for further researches by studying a large number of subjects.

\section{Acknowledgments}

None.

\section{Conflicts of interest}

None.

\section{References}

1. Sinnatamby. C. Last's anatomy Regional \& applied. (10th edn), UK, 1999;p.58-60.

2. Gray H. Anatomy of human body. In: Warren H Lewis (Eds.), (20th edn), Philadelphia, USA. 1918.

3. Solomon L et al. Apley's system of orthopaedics and fracture. (18th edn), London, UK. 2001;pp.303-313.

4. Charles YP, Canavese F, Diméglio A. Skeletal age determination from the elbow during pubertal growth. Orthopade. 2005;34(10):1052-1053.

5. Canale T, James H Beaty. Campbell's operative orthopaedics. (11th edn), Part XI. Chapter 33, Mosby Elsiever,China. 2008;pp.1533-1536.

6. John H Juhl. Paul and Juhl's. Essentials of Radiologic Imaging. (7th edn),Lippincott Williams \& Wilkins, Pennsylvania, USA. 1998;P.8

7. Marak FK, Sangma WB, Singh MS, et al. Roentgenographic study for age estimation in boys and girls of North - Eastern region of India. International Journal of Medical Toxicology \& Legal Medicine. 2008;10(2):38-43.

8. Banerjea AK, Rao MN. Ossification centres at the elbow joint in Bengali girls. Indian Journal of Pediatrics Volume. 1970;37(4):127-133. 